\title{
Prevalence and psychosocial correlates of after-school activities among Chinese adolescents in Hong Kong
}

\section{Cecilia M. S. Ma* and Daniel Tan Lei Shek}

The Hong Kong Polytechnic University, Hong Kong, China

Edited by:

Hatim A. Omar, University of

Kentucky, USA

\section{Reviewed by:}

Stephanie Jean Stockburger,

University of Kentucky, USA

John Andrew Yozwiak, University of

Kentucky, USA

${ }^{*}$ Correspondence:

Cecilia M. S. Ma, HJ431, Department of Applied Social Sciences, The Hong

Kong Polytechnic University, Hong

Kong SAR, China

e-mail: cecilia.ma@polyu.edu.hk

\begin{abstract}
Using a cross-sectional design, this study (a) explores the prevalence of after-school activities among Chinese early adolescents and (b) assesses the relationships between participation in after-school activities, personal well-being, and family functioning. A total of 3,328 Grade 7 students (mean age $=12.59$ years, $S D=0.74$ ) completed a self-administered questionnaire. Results showed that the majority of adolescents returned home under adult supervision. Further analyses showed the associations between after-school activities, positive youth development qualities, academic and school competence, family functioning, and risky behavior. Implications regarding efforts aimed at designing high quality and structured after-school youth programs are discussed.
\end{abstract}

Keywords: after-school activities, positive youth development, Chinese adolescents, family functioning, Hong Kong

\section{INTRODUCTION}

How adolescents spend their time after the school has been examined in the past decades. Generally speaking, previous crosssectional studies have demonstrated the positive influence of after-school activities as well as experiences and youth development outcomes, such as school outcomes, social adjustment, civic engagement, and problem behaviors (1-3). The developmental significance of after-school time activities is further supported in longitudinal research. For instance, Mueller et al. (4) used a longitudinal design to study the relationship between participation in youth program and developmental outcomes (e.g., self-regulation skills and contribution to the society) among eighth to tenth graders. Results showed that adolescents' participation in afterschool program predicted their intention to contribute to the family and community after 2 years. Based on three waves of data, Kort-Butler and Hagewen (5) found that the type of extracurricular activity portfolio affected the trajectories of self-esteem from mid-adolescence to young adulthood.

Despite the growing body of research showing the positive effect of after-school activities on youth development, there are several research gaps in this field. First, existing findings on the relations between after-school experience and adolescents' socio-emotional development failed to assess whether the results vary according to the nature of the activity. Existing studies have mainly confined to the influence of structured activities, such as organized sports, extracurricular activities, and religious groups, which are commonly supervised by adults and governed by rules and goals. Research has shown that adolescents who participated in structured activities showed higher levels of social trust (6), self-esteem (7), decision making skills (8), and lower levels of delinquent behaviors (9) than those who did not participate.

In contrast, little is known about the influence of unstructured activities on adolescents' well-being (e.g., life satisfaction) and perceived school and academic competencies. Unlike structured activities, these activities are often initiated by the participants without adult supervision (e.g., "hanging out", playing, reading, and surfing the internet) $(10-12)$. Larson $(13,14)$ argued that these unstructured activities might also contribute to positive youth development due to its intrinsically motivated and voluntary nature, and thereby promoting open and uncritical peer interactions. This activity might also promote "secondary socialization" that helps youth to be socialized into group norms and membership (14). Unlike the adult-directed activities, children learn how to make their own decisions, solve their own problems, regulate their emotions and get along with friends, and follow rules and norms in the unsupervised context (15). The practice of self-control not only serves as a source of pleasure but also allows children to develop competence and confidence when problems arise $(15,16)$. These activities provide them, who act as "organizers of development" $(17,18)$, a unique context to develop and equip various kinds of positive competencies and skills (14).

Second, as prior research on after-school activity primarily focuses on reducing problem behaviors $(9,19)$, researchers have advocated a strength-based approach for promoting positive outcomes among adolescents $(14,20)$. Studies showed that participation in structured after-school activities was associated with prosocial behavior (21), self-regulation (4), life satisfaction (22), self-esteem (23) and related to fewer depressive symptoms, lower levels of anxiety (24), and less likely to engage in adolescent problem behaviors, such as pornography consumption $(25,26)$, substance use (27), delinquency (28), and internet addiction (29). More research is warranted to explore whether the benefits of participation in after-school activities exist in different dimensions of positive youth development qualities. Given the impact on positive youth development outcomes remains largely unexplored, the current study will examine the relationships between after-school activity and various positive youth developmental outcomes among early Chinese adolescents in Hong Kong.

Third, as most studies are conducted in Western contexts, it is not clear whether the benefits of after-school time activity also 
exist in the Chinese context. Under the influence of Confucianism, Chinese children are encouraged to study at the expense of leisure activity, which is in contrast to the beliefs in the Western culture that leisure activities and play are good ways to reduce physical and psychological stress. Chinese children grow up in a context where diligence is deeply cherished. They believe education as the only way of upward social mobility. They learn to work hard and make maximum use of time for study. This can be reflected in a Chinese proverb "Diligence has its reward; play as no advantages" ( qin you gong, xi wu yi). The desire to excel academically is further supported by a study of at least $80 \%$ of middle school Chinese students spent over $8 \mathrm{~h}$ at school, which was longer than their parents spend at work (30).

Under the ever-increasing academic pressure, Chinese children have to do homework and prepare for examinations until late at night. Facing the competitive academic atmosphere and limited university places, Chinese children, especially those from affluent families, are asked to enroll in extracurricular tutorial classes after school and during weekend. Three major stressors were reported by Chinese students when facing such pressure, including "over-scheduling," "insufficient sleep," and "little time for exercise" $(30,31)$. Researchers advocated the adoption of the developmental-ecological approach to understand the nature of developmental process in a given context $(32,33)$. This information "helps identifying individuals' preparedness to engage in specific developmental process. . .how might other factors such as age, personality, culture, gender, and SES shape initial dispositions, youths experience and participate in an activity" [(15), p. 179].

The lack of empirical studies in Chinese contexts is further supported when doing literature search in electronic databases. A computer search of PsycINFO database in August 2014 using "after-school time" and "after-school hours" showed that there were 9 and 4 citations, respectively. These figures clearly represented the needs to study the impact of after-school time activity on Chinese adolescents' well-being. Given that after-school activity provides a unique arena for structuring adolescent development (5), this paper, therefore, attempts to fill the research gap by assessing the relations of after-school activity and adolescents' outcomes in a non-Western city, Hong Kong.

To date, with an exception of a few studies $(34,35)$, studies on the pattern of after-school activities among Chinese adolescents is scarce. Based on a longitudinal design, Shek (35) found that the level of after-school activity without adult supervision increased from 14.5 to $26.9 \%$ over 3 years among 2,559 Chinese early adolescents (Grade 7). In particular, he found that adolescents' after-school time use was a significant factor in predicting of parent-child relational qualities and their psychological wellbeing. A limitation of this study was the inability to measure differences in developmental outcomes as a function of nature of afterschool activity. Previous research also shows that the relation of after-school activity involvement and problem behaviors varied by activity structure (36). Results indicated that a positive association between participating in unstructured and unsupervised activities and deviant behavior $(19,36,37)$. Although prior research (35) underscored the relationship between after-school activity, family (e.g., parenting style and parent-adolescent relationship) and individual outcomes (e.g., psychological well-being), the nature of activity, particularly unstructured activity (e.g., wandering street alone), was not tested.

Theoretically, it is expected that the associations differ across activity types. Developmental researchers argued that the influences of after-school time activity may vary due to the environment that fails to meet the adolescents' developmental needs ( 7 , $38,39)$. Prior studies showed that poor family functioning was associated with adolescents' problem and risky behaviors $(25,26$, 29), poor school adjustment, and fewer positive developmental outcomes (35, 40, 41). Farb and Matjasko (42) noted that "adult supervision could be investigated as a moderator or mediator of participation with developmental outcomes" (p. 44). It seems that Chinese adolescents, who perceived higher family functioning, tend to receive better parental supervision and care, thereby likely to engage in more academic and structured activities than those who perceived lower level of family functioning. Along with this line, it is important to examine the characteristics of the activities $(42,43)$. As such, the current study will examine the relationship between family functioning and after-school time activity.

In light of the above considerations, the purpose of the present study was to assess the relationships between participation in afterschool activity and personal well-being (i.e., positive youth development, risk behavior, life satisfaction, and school adjustment indicators) and family functioning among junior Chinese adolescents in Hong Kong. Three research questions were addressed in this paper:

1. What do Chinese adolescents do after school? What is the pattern of after-school activities engaged by the students?

2. Do adolescents engaging in different after-school activities have different levels of personal well-being indexed by positive youth development qualities, risk behavior, and perceived academic and school competence?

Based on the previous literature (35), it was expected that compared with those who participated in activities with peers and spent time alone, students who participated in after-school activities or spent times with adults would report higher levels of psychological well-being (i.e., positive youth development qualities, life satisfaction, Hypothesis 1a), school adjustment (i.e., perceived school and academic competence, Hypothesis 1b), and a lower level of risky behavior (Hypothesis 1c).

3. Do adolescents engaging in different after-school activities have different perceived family functioning?

Based on the prediction of family theories (e.g., family monitoring facilitates adolescent development) and previous research findings, it was predicted that adolescents participate in more structured activities after school would have better perceived family functioning than those participate in unstructured activities (Hypothesis 2).

\section{MATERIALS AND METHODS}

This study used data from the first-wave data of a 6-year longitudinal study, which attempted to examine the personal, social, and family well-being and developmental trends of adolescents in Hong Kong. In the study, a multi-stage cluster sampling method 
Table 1 | Demographic information of the participants.

\begin{tabular}{lrr}
\hline & $\boldsymbol{n}$ & $\%$ \\
\hline Gender & & \\
Male & 1,719 & 52.2 \\
Female & 1,572 & 47.8 \\
Place of birth & & \\
Hong Kong & 2,590 & 78.3 \\
Mainland China & 655 & 19.8 \\
Others & 64 & 1.9 \\
Parental marital status & & \\
First marriage & 2,781 & 84.4 \\
Divorced & 209 & 6.3 \\
Separated & 73 & 2.2 \\
Remarried & 129 & 3.9 \\
Others & 104 & 3.2 \\
Receiving financial aids & & \\
Yes & 225 & 78.3 \\
No & 2,606 & 13.9 \\
Others & 465 & \\
\hline
\end{tabular}

was used $(44,45)$. A total of 28 secondary schools were randomly selected based on the school list obtained from The Hong Kong Education Bureau (http://www.edb.gov.hk).

\section{PARTICIPANTS}

A total of 3,328 Grade 7 students (mean age $=12.59$ years, $\mathrm{SD}=0.74$ ), including 1,719 boys and 1,572 girls, were invited to complete a self-administered questionnaire. Thirty-seven students did not indicate their gender. The demographic information of the participants is summarized in Table 1.

\section{INSTRUMENTS AND PROCEDURES}

Before the data collection, ethical approval from the Hong Kong Polytechnic University Review Board, parental/guardian, school, and participant consent was obtained. A standard protocol was used to ensure the surveys were administered uniformly by the research assistants. Students were informed that participation was voluntary and confidentiality of their responses was assured. During the data collection, students found no difficulties in understanding about the term "after-school activity."

\section{Personal well-being indicators}

The Chinese Positive Youth Development Scale (CPYDS). The 45-item short form of the Chinese Positive Youth Development Scale (CPYDS) is used to assess 15 positive youth development constructs, including bonding (e.g., When I need help, I trust my parents will help me), resilience (e.g., When I face difficulty, I will not give up easily), social competence (e.g., I know how to communicate with others), recognition for positive behavior (e.g., When I complete my tasks, teachers will praise me), emotional competence (e.g., When I am unhappy, I can appropriately show my emotions), cognitive competence (e.g., I believe there is a solution for any problem), behavioral competence (e.g., I know how to say no to unfair requests), moral competence (e.g., I have high moral expectation about my behavior), self-determination (e.g., I am able to make wise choices), self-efficacy (e.g., I have little control of things that happen in my life), clear and positive identity (e.g., I can do things as good as others), beliefs in the future (e.g., I have confidence to solve my future problems), prosocial involvement (e.g., In this school, students are encouraged to have voluntary service), prosocial norms (e.g., I care about unfortunate people in the society), and spirituality (e.g., To me, life is very dull versus very exciting). All subscales were measured by using a six-point Likert scale, except spirituality (i.e., seven-point Likert scale). Details of the items can be seen in Shek et al. $(46,47)$. A higher score indicated better positive youth development. This scale contains no reverse-scored items. Alpha of this scale in the study was 0.85 (mean inter-item correlation $=0.37$ ).

Life satisfaction. Five items were used to assess the life satisfaction of the participants (e.g., I am very satisfied with my living conditions). A composite score was calculated to obtain the mean of the overall life satisfaction (48). Alpha of this scale was 0.85 (mean inter-item correlation $=0.55)$.

Perceived academic and school performance (ASC). Three items were used to assess participants' perceptions on their ASC (e.g., Are you satisfied with your own present academic performance?). A composite score was calculated by averaging all item scores in order to obtain the mean of the overall ASC. Alpha of this scale was 0.67 (mean inter-item correlation $=0.40)$.

Delinquent behavior. Participants were asked to report how often they engaged in 12 types of delinquent behavior (i.e., stealing, cheating, truancy, running away from home, damaging others' properties, assault, having sexual intercourse with others, gang fighting, speaking foul language, staying outside the home overnight without parental consent, strong arming others, and trespassing) in the past year. Alpha of this scale was 0.70 (mean inter-item correlation $=0.25$ ).

Substance use. Participants were asked to assess their frequency of using eight types of substance (i.e., alcohol, tobacco, ketamine, cannabis, cough mixture, organic solvent, pills such as ecstasy, and methaqualone) in the past 12 months. A composite score was calculated to obtain the mean of the overall substance use. Alpha of this scale was 0.50 (mean inter-item correlation $=0.35$ ).

\section{Family well-being indicator}

The Chinese family assessment instrument (CFAI). The nineitem short form of the Chinese family assessment instrument (CFAI) is used to assess three dimensions of family functioning, including mutuality (e.g., Family members love each other), communication (e.g., Parents often talk to their children), and harmony (e.g., Family members get along well). A five-point Likert scale is used to measure these subscales. A higher total score on the subscales showed a higher level of positive family functioning. The reliability and validity of the scale was shown in other publications $(47,49,50)$. Alpha of this scale was 0.90 (mean inter-item correlation $=0.50)$.

\section{After-school activity}

Participants were asked to report how they usually spend their time after school by using a single-item indicator (i.e., $1=$ returned 
Table 2 | The prevalence of the after-school time activities.

\begin{tabular}{lc}
\hline & Overall (\%) \\
\hline Returned home with the presence of adults & 42.3 \\
Returned home without the presence of adults & 12.5 \\
Returned home with the presence of siblings & 10.9 \\
Participated in extracurricular activity & 23.5 \\
Socializing with friends without the presence of adults & 9.9 \\
Wandering the streets alone & 0.9
\end{tabular}

home with the presence of adult; $2=$ returned home without the presence of adult; $3=$ returned home with the presence of siblings only; $4=$ extracurricular activity; $5=$ socializing with friends without the presence of adults; $6=$ wandering the streets alone).

\section{DATA ANALYSIS STRATEGY}

All analyses were performed using SPSS 19.0. Descriptive statistics were conducted to describe all variables. To analyze activity type in terms of psychosocial well-being, academic and school performance, and risky behaviors, a series of multivariate analysis of covariance (MANCOVA) followed by analysis of variance (ANOVA) was used to test the differences in activity type on the outcome measures. Gender was included in the above analyses as covariate. Post hoc analysis was performed to avoid an inflated Type I error by adjusting Bonferroni $p$-values $(p<0.01)$.

\section{RESULTS}

As shown in Table 2, 42\% of early adolescents returned home under adult supervision, $24 \%$ participated in extracurricular activity, $13 \%$ stayed at home without the presence of adults, about $21 \%$ spent time with siblings and friends, less than $1 \%$ wandered the streets along. Compared to the findings in the West $(51,52)$, more Chinese adolescents participated in adult-supervised after-school activity.

Tables 3 and 4 present the differences in psychosocial wellbeing, ASC, and risky behaviors regarding the types of afterschool activity. The covariate effect on gender was significant $\left(F_{(1,1665)}=9.61, p<0.01\right)$. There was a significant main effect of the type of activity on all outcome variables $\left(F_{(5,1665)}=3.80\right.$, $p<0.01)$. Adolescents participated in extracurricular activity and stayed at home under adults' supervision scored significantly higher levels in all positive youth development qualities, ASC, family functioning, and lower level in risk behaviors as compared to other types of after-school time activity. In general, participants in structured activities (i.e., staying at home with adults and participating in extracurricular activity) scored higher in positive youth development qualities, ASC, perceived family functioning, and lower in risky behavior (i.e., past substance use and delinquency) as compared to those who participated in unstructured activities (i.e., socializing with peers and wandering street alone). The effect size (partial eta squared) results were shown in Tables 3 and 4. In general, the effect sizes for all measured variables were small, ranging from 0.02 to 0.11 (53). In short, Hypotheses $1 \mathrm{a}, 1 \mathrm{~b}$, $1 c$, and 2 were supported.

\section{DISCUSSION}

The purposes of the current study were (a) to describe the pattern of after-school time activity participation among Chinese early adolescents and (b) to assess the relationships between participation in after-school activities, personal well-being (i.e., positive youth development, life satisfaction, school adjustment, and risk behavior), and family functioning. There were several unique features of the study. First, a large and representative sample was used in this study. Second, in view of the paucity of research in different Chinese contexts, the present study extends the existing literature. Third, validated measures of positive youth development, adolescent risk behavior, and family functioning were used. Finally, both personal and family well-being indicators were covered in this study.

A majority of the respondents reported that they usually returned home with the presence of adults. Participation in extracurricular activity was the second most prevalent activity, followed by staying at home with and without others. The results of the present study were consistent with Shek's findings (35) using a similar sample $(34.7 \%)$. These results are higher as compared to the study in Western contexts $(51,52)$. The high level of returning home under adult supervision might be related to the emphasis of scholastic achievement in Chinese contexts $(54,55)$. Private tutoring (e.g., hiring English teacher) is common in Chinese families. Chinese parents often ask their children to spend time working at home for school, such as doing homework, preparing quiz, and examinations in order to achieve school success. Also, it is a common cultural belief that kids will become delinquent if they hang out in the streets too often (56).

Another possible explanation can be operated in terms of familistic values (i.e., mutual support and hierarchical pattern of authority) in Chinese contexts (57). Spending time together with family members is an attribute of a happy and harmonious family $(58,59)$. It also relates to healthy family functioning and serves as a protective factor against Chinese adolescents' suicide ideation $(60,61)$. This study demonstrates the cultural characteristics of participants should be considered when studying the pattern of adolescents' after-school time activity.

In the present study, socializing with friends alone was the second least popular activity. Adolescence is a period of exploration, experimentation, and searching of identity (62-64). To achieve identity formation and foster positive peer relations, adolescents participate in leisure and recreational activities and aimlessly wandering the street in their daily lives. Given the younger age of the sample in the present study, it is expected that the prevalence of social activity increase over time as socializing increase with age during the adolescence $(65,66)$. This is further supported by longitudinal studies in which healthy use of after-school time is a good indicator of a positive developmental trajectory throughout adolescence, regardless of the Western $(67,68)$ and Chinese contexts (35). Future research should adopt a longitudinal design to study the change of after-school activity among Chinese adolescents.

Although the prevalence of after-school activity without supervision is low, researchers noted this specific group, especially those who wandered the streets alone, deserves attention (43). Evidence shows significant associations between unsupervised after-school 
Table 3 | Differences in psychological well-being by types of after-school time activity.

\begin{tabular}{|c|c|c|c|c|c|c|c|c|}
\hline \multirow[t]{2}{*}{ Variables } & \multirow{2}{*}{$\begin{array}{c}\begin{array}{l}\text { Home with } \\
\text { adults }^{\mathrm{a}}\end{array} \\
M \text { (SD) }\end{array}$} & \multirow{2}{*}{$\begin{array}{l}\text { Home without } \\
\text { adults }^{\text {b }} \\
M(\mathrm{SD})\end{array}$} & \multirow{2}{*}{$\begin{array}{c}\begin{array}{l}\text { Home with } \\
\text { siblings only }\end{array} \\
M \text { (SD) }\end{array}$} & \multirow{2}{*}{$\begin{array}{l}\begin{array}{l}\text { Extra-curricular } \\
\text { activity }^{d}\end{array} \\
M \text { (SD) }\end{array}$} & \multirow{2}{*}{$\begin{array}{l}\begin{array}{l}\text { Socializing with } \\
\text { friends }\end{array} \\
M(\mathrm{SD})\end{array}$} & \multirow{2}{*}{$\begin{array}{l}\begin{array}{l}\text { Wandering streets } \\
\text { alone }^{f}\end{array} \\
M(\mathrm{SD})\end{array}$} & \multirow[t]{2}{*}{$\boldsymbol{F}$} & \multirow[t]{2}{*}{$\eta^{2}$} \\
\hline & & & & & & & & \\
\hline $\mathrm{BO}$ & $4.88^{\text {abef }}(0.77)$ & 4.66 abdef $(0.91)$ & $4.71^{\text {cef }}(0.78)$ & $4.91^{\text {abdef }}(0.73)$ & $4.40^{\mathrm{abcde}}(0.95)$ & $3.80^{\mathrm{abcdf}}(0.91)$ & $16.66^{* *}$ & 0.05 \\
\hline $\mathrm{RE}$ & $4.82^{\text {abef }}(0.84)$ & $4.50^{\mathrm{abdf}}(0.92)$ & $4.64^{c f}(0.85)$ & $4.85^{\text {bdef }}(0.75)$ & $4.33^{\text {acde }}(0.89)$ & $3.74^{\mathrm{abcdf}}(0.93)$ & $17.55^{* *}$ & 0.05 \\
\hline SC & $4.84^{\text {acf }}(0.83)$ & $4.76^{f}(0.89)$ & $4.74(0.81)$ & $4.92^{\text {bcdf }}(0.77)$ & $4.74(0.90)$ & $4.05^{\mathrm{abcdf}}(1.06)$ & $4.25^{* *}$ & 0.01 \\
\hline $\mathrm{EC}$ & $4.44^{\text {aef }}(0.88)$ & $4.28^{\text {bef }}(0.91)$ & $4.30^{\text {cef }}(0.84)$ & $4.47^{\text {def }}(0.86)$ & $3.99^{\text {abcde }}(1.04)$ & $3.45^{\mathrm{abcdf}}(1.00)$ & $11.40 * *$ & 0.03 \\
\hline $\mathrm{CC}$ & $4.43^{\mathrm{ae}}(0.86)$ & $4.36(0.88)$ & $4.34(0.86)$ & $4.51^{\text {def }}(0.81)$ & $4.10^{\text {ade }}(1.03)$ & $3.76^{\mathrm{df}}(1.09)$ & $7.13^{* *}$ & 0.02 \\
\hline $\mathrm{BC}$ & $4.62^{\mathrm{ae}}(0.76)$ & $4.63^{\text {be }}(0.79)$ & $4.56^{c}(0.78)$ & $4.73^{\text {de }}(0.74)$ & $4.34^{\text {abde }}(0.91)$ & $3.79^{\mathrm{abcd}}(1.11)$ & $9.03 * *$ & 0.03 \\
\hline $\mathrm{MC}$ & $4.52^{\text {abe }}(0.82)$ & $4.29^{\text {abde }}(0.92)$ & $4.38^{\text {cde }}(0.83)$ & $4.63^{\text {bcdef }}(0.85)$ & $4.05^{\mathrm{abcde}}(0.89)$ & $3.83^{\mathrm{df}}(1.26)$ & $15.02 * *$ & 0.04 \\
\hline SD & $4.58^{\text {aef }}(0.82)$ & $4.45^{b f}(0.96)$ & $4.49^{c f}(0.83)$ & $4.62^{\text {def }}(0.84)$ & $4.26^{\text {adef }}(0.92)$ & $3.57^{\text {abcdef }}(1.16)$ & $8.61 * *$ & 0.03 \\
\hline SE & $4.45^{\mathrm{af}}(0.90)$ & $4.32(0.96)$ & $4.30(0.90)$ & $4.49^{d f}(0.84)$ & $4.25(0.83)$ & $3.64^{\text {adf }}(1.25)$ & $5.19 * *$ & 0.02 \\
\hline PN & $4.82^{\text {abef }}(0.83)$ & $4.56^{\text {abde }}(0.91)$ & $4.71^{\mathrm{ce}}(0.87)$ & $4.91^{\text {bdef }}(0.78)$ & 4.29abcde (1.04) & $4.07^{\text {adf }}(0.98)$ & $17.33^{* *}$ & 0.05 \\
\hline $\mathrm{SPg}$ & $5.38^{\text {abef }}(1.20)$ & $4.88^{\mathrm{abd}}(1.42)$ & $5.14^{\text {cdef }}(1.28)$ & $5.52^{\text {bcdef }}(1.09)$ & $4.66^{\text {acde }}(1.46)$ & $3.86^{\text {acdf }}(1.30)$ & $19.84 * *$ & 0.06 \\
\hline LS & $4.18^{\mathrm{abce}}(1.00)$ & $3.80^{\mathrm{abd}}(1.20)$ & $3.90^{\mathrm{ac}}(1.00)$ & $4.13^{\text {bde }}(1.04)$ & $3.62^{\text {ade }}(1.13)$ & 3.49 (1.22) & $12.12^{* *}$ & 0.04 \\
\hline
\end{tabular}

$B O$, bonding; $R E$, resilience; $S C$, social competence; $P B$, recognition for positive behavior, $E C$, emotional competence; $C C$, cognitive competence; $B C$, behavioral competence; $M C$, moral competence; SD, self-determination; SE, self-efficacy; SI, clear and positive identity; BF, beliefs in the future; $P I$, prosocial involvement; $P N$, prosocial norms; SP, spirituality; LS, life satisfaction.

${ }^{* *} p<0.01$.

$a, b, c, d, e$, Means sharing the same superscript indicate significant post hoc differences in the Bonferroni test $(p<0.05)$.

${ }^{9}$ This is a seven-point Likert scale.

Table 4 | Differences in risky behaviors, family functioning, and perceived academic competence by types of after-school time activity.

\begin{tabular}{|c|c|c|c|c|c|c|c|c|}
\hline \multirow[t]{2}{*}{ Variables } & $\begin{array}{l}\text { Home with } \\
\text { adults }^{\mathrm{a}}\end{array}$ & $\begin{array}{l}\text { Home without } \\
\text { adults }^{b}\end{array}$ & $\begin{array}{l}\text { Home with } \\
\text { siblings only }\end{array}$ & $\begin{array}{l}\text { Extra-curricular } \\
\text { activity }^{d}\end{array}$ & $\begin{array}{l}\text { Socializing with } \\
\text { friends }\end{array}$ & $\begin{array}{l}\text { Wandering } \\
\text { streets alone }^{f}\end{array}$ & $F$ & $\eta^{2}$ \\
\hline & $M(\mathrm{SD})$ & $M(\mathrm{SD})$ & $M(\mathrm{SD})$ & $M(\mathrm{SD})$ & $M(\mathrm{SD})$ & $M(\mathrm{SD})$ & & \\
\hline$D R \cup G$ & $0.05^{\text {aef }}(0.11)$ & $0.08^{\text {bef }}(0.15)$ & $0.07^{\text {cef }}(0.22)$ & $0.07^{\text {def }}(0.15)$ & $0.22^{\text {abcde }}(0.33)$ & $0.22^{\mathrm{abcdf}}(0.21)$ & $29.27^{* *}$ & 0.08 \\
\hline $\mathrm{DE}$ & $0.28^{\mathrm{ae}}(0.34)$ & $0.37^{\text {be }}(0.42)$ & $0.36^{\mathrm{ce}}(0.35)$ & $0.32^{\text {de }}(0.37)$ & $0.76^{\text {abcde }}(0.73)$ & $0.70^{\text {ade }}(0.49)$ & $41.19 * *$ & 0.11 \\
\hline CFAI & $3.98^{\text {abef }}(0.75)$ & $3.65^{\text {abdef }}(0.81)$ & $3.80^{\text {cef }}(0.72)$ & $3.88^{\text {bdef }}(0.78)$ & $3.20^{\text {abcde }}(0.84)$ & $2.78^{\mathrm{abcdf}}(0.63)$ & $33.91 * *$ & 0.09 \\
\hline
\end{tabular}

Drug, past substance use; DE, past delinquency behaviors; CFAl, Chinese family functioning; ASC, academic and school competence.

${ }^{* *} p<0.01$.

$a, b, c, d, f, f$ Means sharing the same superscript indicate significant post hoc differences in the Bonferroni test $(p<0.05)$.

activity and early involvement in poor academic performance, substance use, and sexual behavior $(14,20,69)$. This is further supported in a longitudinal study by showing the lower rates of criminal arrests and reducing chance to spent time with deviant peers among youth who participated in at least one extracurricular activity (70). In particular, Shek (35) found that unsupervised after-school activities, such as home alone and socializing with friends, are associated with poor parent-child relational qualities and psychological well-being. Our study shows the positive relations between supervised after-school activities and Chinese adolescents' developmental outcomes. Of course, how to encourage a balance between structured activities and allowing freedom for adolescents to grow is an issue to be considered.

The results give support to the hypotheses that students who participated in after-school activities or spent time under adult supervision reported high levels of personal well-being in terms of positive youth development qualities, life satisfaction, perceived school, family functioning and academic adjustment, and a lower level of problem behavior as compared to those who spent time with peers or alone. When adolescents feel connectedness with adults, they are more likely to feel secure about themselves, to have prosocial attitudes and behaviors and to achieve academic 
success $(6,21,71)$. The present study demonstrates that the nature of activity may be an important factor when studying its influence on adolescent development. More research on studying the components of adolescent after-school activities is warranted.

Results also showed that family functioning was better in students who engaged in structured activities. Based on the predictions of different family functioning theories, family functioning such as family rules and parental supervision governs adolescent development. The present findings are in line with such predictions. It can be reasoned that positive family functioning would shape positive parenting expectations, which would eventually constitute family protective factors for adolescent development.

Theoretically speaking, adolescent development is the product of multidimensional and reciprocal interaction between an individual and his/her environment $(4,7)$. The present findings show the relationship between participation in after-school time activities and adolescents' developmental outcomes. The results of the study support the critical role of the individual and contextual assets on adolescent development (20) and highlight the need for future research to consider the nature of after-school activities. Practically, this may serve as an indicator of adolescent development in terms of their personal and family well-being. Practitioners and educators can use this indicator when designing high quality and structured after-school youth programs that meet the individual needs and characteristics in the future.

There are several limitations of the study. The first is that we only used one item to assess the pattern of adolescents' afterschool time activity. Although this approach has been adopted in previous study (6), future research should incorporate other measurement tools (e.g., the Children's Assessment of Participation and Enjoyment, 11) to help clarify the multiple dimensions (e.g., recreational activities, social activities, skill-based activities) and features (e.g., intensity, duration, breadth) of after-school time activity and its relative effects on adolescents' development and behaviors.

A second limitation is that the data are cross-sectional. Causal direction of effects based on the current results cannot be made. Future research should examine the effects of after-school activity by adopting a longitudinal design. Another limitation is the use of self-report measures. Future research should examine the influence of social desirability bias. Third, the effect size was generally small in the present study. Perhaps, this may be related to the large sample size. To further assess the influence of after-school activity on adolescents' developmental outcomes, more research in this area is needed. Finally, possible protective factors in mediating the relationship of activity participation and adolescents' developmental outcomes are suggested to be included. Prior findings show that the relationship does vary by parental monitoring, peer group characteristics, and neighborhood safety $(32,51,68,69,72-$ 74). More research is warranted to replicate and extend the present findings in Chinese contexts.

In conclusion, the findings of the current study highlight the importance of providing organized and supervised after-school activity to early Chinese adolescents. The results show the relationship between after-school activity and developmental outcomes. This study sheds light on this area of research and extends the literature that is mostly derived from Western contexts.

\section{ACKNOWLEDGMENTS}

The preparation for this paper and the Project P.A.T.H.S. were financially supported by The Hong Kong Jockey Club Charities Trust. The authorship is equally carried between the first author and second author.

\section{REFERENCES}

1. Harel-Fisch Y, Walsh SD, Fogel-Grivald H, Amitai G, Picket W, Molsch M, et al. Negative school perceptions and involvement in school bullying: a universal relationship across 40 countries. JAdolesc (2011) 34:639-52. doi:10.1016/ j.adolescence.2010.09.008

2. Sellström E, Bremberg S. Is there a "school effect" on pupil outcomes? A review of multilevel studies. J Epidemiol Community Health (2006) 60:149-55. doi:10.1136/jech.2005.036707

3. Patrick H, Ryan A, Kaplan A. Early adolescents' perceptions of the classroom social environment, motivational beliefs, and engagement. JEduc Psychol (2007) 99:83-98. doi:10.1037/0022-0663.99.1.83

4. Mueller MK, Phelps E, Bowers EP, Agans JP, Urban JB, Lerner RM. Youth development program participation and intentional self-regulation skills: contextual and individual bases of pathways to positive youth development. JAdolesc (2011) 34:1115-25. doi:10.1016/j.adolescence.2011.07.010

5. Kort-Butler LA, Hagewen KJ. School-based extracurricular activity involvement and adolescent self-esteem: a growth-curve analysis. J Youth Adolesc (2011) 40:568-81. doi:10.1007/s10964-010-9551-4

6. Flanagan C, Gill S, Gallay LS. Social participation and social trust in adolescence: the importance of heterogeneous encounters. In: Omoto A, editor. Social Participation in Processes of Community Change and Social Action. The Claremont symposium on Applied Social Psychology. Mahwah, NJ: Lawrence Erlbaum Associates Publishers (2005). p. 149-66.

7. Eccles JS, Barber BL, Stone M, Hunt J. Extracurricular activities and adolescent development. J Soc Issues (2003) 59:865-89. doi:10.1046/j.0022-4537.2003. 00095.x

8. Busseri MA, Rose-Krasnor L, Willoughby T, Chalmers H. A longitudinal examination of breadth and intensity of youth activity involvement and successful development. Dev Psychol (2006) 42:1313-26. doi:10.1037/0012-1649. 42.6.1313

9. Crean HF. Youth activity involvement, neighborhood adult support, individual decision making skills, and early adolescent delinquent behaviors: testing a conceptual model. J Appl Dev Psychol (2012) 33:175-88. doi:10.1016/j.appdev.2012. 04.003

10. Brown M, Gordon WA. Impact of impairment on activity patterns of children. Arch Phys Med Rehabil (1987) 68:828-32.

11. King G, Law M, King S, Hurley P, Hanna S, Kertoy M, et al. Children's Assessment of Participation and Enjoyment (CAPE) and Preferences for Activities of Children $(P A C)$. San Antonio, TX: Harcourt Assessment (2004).

12. King G, Law M, Hanna S, King S, Hurley P, Rosenbaum P, et al. Predictors of the leisure and recreation participation of children with physical disabilities: a structural equation modeling analysis. Child Health Care (2004) 35:209-34. doi:10.1207/s15326888chc3503_2

13. Larson RW. Beeping children and adolescents: a method for studying time use and daily experience. J Youth Adolesc (1983) 18:511-30. doi:10.1007/ BF02139071

14. Larson RW. Toward a psychology of positive youth development. Am Psychol (2000) 55:170-83. doi:10.1037/0003-066X.55.1.170

15. Gray P. The decline of play and the rise of psychopathology in children and adolescents. Am J Play (2011) 3:443-63.

16. Vygotsky L. The role of play in development. In: Cole M, John-Steiner V, Scibner S, Souberman E, editors. Mind in Society: The Development of Higher Psychological Processes. Cambridge, MA: Harvard University Press (1978). p. 92-104.

17. Collins WA, Gunnar MR. Social and personality development. Am Rev Psychol (1990) 41:387-416. doi:10.1146/annurev.ps.41.020190.002131

18. Hauser ST, Smith HF. The development and experience of affect in adolescence. I Am Psychoanal Assoc (1991) 39:131-65.

19. Mahoney JL, Stattin H. Leisure activities and adolescent antisocial behavior: the role of structure and social context. J Adolesc (2000) 23:113-27. doi:10.1006/jado.2000.0302 
20. Lerner RM, Almerigi HB, Theokas C, Lerner JV. Positive youth development: a view of the issues. J Early Adolesc (2005) 25:10-6. doi:10.1177/ 0272431604273211

21. Morrissey KM, Werner-Wilson RJ. The relationship between out-of-school activities and positive youth development: an investigation of the influences of co communities and family. Adolescence (2005) 40:67-85.

22. Leversen I, Danielsen AG, Birkeland MS, Samdal O. Basic psychologicalneed satisfaction in leisure activities and adolescents' life satisfaction. J Youth Adolesc (2012) 41(12):1588-99. doi:10.1007/s10964-012-9776-5

23. Richman EL, Shaffer DR. If you let me play sports: how might sports participation influence the self-esteem of adolescent females? Psychol Women Q (2000) 24:189-99. doi:10.1111/j.1471-6402.2000.tb00200.x

24. Mahoney JL, Schweder AE, Stattin H. Structured after-school activities as a moderator of depressed mood for adolescents with detached relations to their parents. J Community Psychol (2002) 30:69-86. doi:10.1002/jcop.1051

25. Shek DT, Ma CM. Consumption of pornographic materials among Hong Kong early adolescents: a replication. ScientificWorldJournal (2012) 2002:406063. doi:10.1100/2012/406063

26. Shek DT, Ma CM. Consumption of pornographic materials among early adolescents in Hong Kong: profiles and psychosocial correlates. Int J Disabil Hum Dev (2012) 11:143-50. doi:10.1515/ijdhd-2012-0024

27. Shek DT, Ma CM. Substance abuse in junior secondary school students in Hong Kong: prevalence and psychosocial correlates. Int J Child Health Hum Dev (2012) 4:433-42.

28. Shek DT, Ma CM, Tang CY. Delinquency and problem behavior intention among early adolescents in Hong Kong: profiles and psychosocial correlates. Int J Disabil Hum Dev (2012) 11:151-8. doi:10.1515/ijdhd-2012-0017

29. Yu L, Shek DT. Internet addiction in Hong Kong adolescents: a three-year longitudinal study. J Pediatr Adolesc Gynecol (2013) 26:S10-7. doi:10.1016/j.jpag. 2013.03.010

30. China Youth and Children Research Center. Recreational and Leisure Time Activities Among Young Chinese People. Beijing: China Youth and Children Research Center (2008).

31. China Youth and Children Research Center. Living Habits of Children and Adolescents in Large Chinese Cities. Beijing: China Youth and Children Research Center (2009).

32. Bohnert AM, Richards M, Kohl K, Randal E. Relationships between discretionary time activities, emotional experiences, delinquency and depressive symptoms among urban African American adolescents. J Youth Adolesc (2009) 38:587-601. doi:10.1007/s10964-008-9336-1

33. Luthar SS, Shoum KA, Brown PJ. Extracurricular involvement among affluent youth: a scapegoat for "ubiquitous achievement pressures"? Dev Psychol (2006) 42:583-97. doi:10.1037/0012-1649.42.3.583

34. Shek DT, Lee TY. Perceived parental control processes in Chinese adolescents: implications for positive youth development programs in Hong Kong. Int J Adolesc Med Health (2006) 18:505-19. doi:10.1515/IJAMH.2006.18.3.493

35. Shek DT. After-school time and perceived parental control processes, parentadolescent relational qualities, and psychological well-being in Chinese adolescents in Hong Kong. Fam Ther (2007) 34:107-26.

36. Rorie M, Gottfredson DC, Cross A, Wilson D, Connell NM. Structure and deviancy training in after-school programs. J Adolesc (2011) 34:105-17. doi: 10.1016/j.adolescence.2010.01.007

37. Osgood DW, Wilson JK, Bachman JG, O’Malley PM, Johnson LD. Routine activities and individual deviant behavior. Am Sociol Rev (1996) 61:635-55. doi: $10.2307 / 2096397$

38. Eccles JS, Midgley C, Wigfield A, Buchanan CM, Reuman D, Flanagan C, et al. Development during adolescence: the impact of stage-environment fit on adolescents experiences in schools and families. Am Psychol (1993) 48:90-101. doi:10.1037/0003-066X.48.2.90

39. Mahoney JL, Vandell DL, Simpkins SD, Zarrett N. Adolescent out-of-school activities. 3rd ed. In: Lerner RM, Steinberg L, editors. The Handbook of Adolescent Psychology: Vol. 2. Contextual Influences on Adolescent Development. Hoboken, NJ: John Wiley \& Sons Inc (2009). p. 228-69.

40. Farrington DP, Loeber R. Epidemiology of juvenile violence. Child Adolesc Psychiatr Clin N Am (2000) 9:733-48.

41. Henderson CE, Dakof GA, Schwartz SJ, Liddle HA. Family functioning, selfconcept, and severity of adolescent externalizing problems. J Child Fam Stud (2006) 15:721-31. doi:10.1007/s10826-006-9045-x
42. Farb AF, Matjasko JL. Recent advances in research on school-based extracurricular activities and adolescent development. Dev Rev (2012) 32:1-48. doi:10. 1016/j.dr.2011.10.001

43. Mahoney JL, Larson RW, Eccles JS. Organized Activities as Contexts of Development: Extracurricular Activities, After-School, and Community Programs. Mahwah, NJ: Erlbaumm (2005).

44. Kalton G. Introduction to Survey Sampling. Beverly Hills, CA: Sage Publication (1983).

45. Stopher PR. Collecting, Managing, and Assessing Data Using Sample Surveys. Cambridge, MA: Cambridge University Press (2012).

46. Shek DT, Siu AM, Lee TY. The Chinese positive youth development scale: a validation study. Res Soc Work Pract (2007) 12(3):380-91. doi:10.1177/ 1049731506296196

47. Shek DT, Ma CM. Dimensionality of the Chinese positive youth development scale: confirmatory factor analyses. Soc Indic Res (2010) 98:41-59. doi:10.1007/s11205-009-9515-9

48. Diener E, Emmons RA, Larsen RJ, Griffin S. The satisfaction with life scale. J Pers Assess (1985) 49(1):71-5. doi:10.1207/s15327752jpa4901_13

49. Shek DT, Ma CM. The Chinese family assessment instrument (C-FAI): hierarchical confirmatory factor analyses and factorial invariance. Res Soc Work Pract (2010) 20:112-23. doi:10.1177/1049731509355145

50. Siu AM, Shek DT. Psychometric properties of the Chinese family assessment instrument in Chinese adolescents in Hong Kong. Adolescence (2005) 40:817-30.

51. Flannery DJ, Williams LL, Vazsonyi AT. Who are they with and what are they doing? Delinquent behavior, substance abuse, and early adolescents' after-school time. Am J Orthopsychiatry (1999) 69:247-53. doi:10.1037/h0080426

52. Taverno Ross SE, Dowda M, Colabianchi N, Saunders R, Pate RR. After-school setting, physical activity, and sedentary behavior in 5th grade boys and girls. Health Place (2012) 18:951-5. doi:10.1016/j.healthplace.2012.06.013

53. Cohen J. Statistical Power Analysis for the Behavioral Sciences. 2nd ed. Hillsdale, NJ: Lawrence Earlbaum Associates (1988).

54. Hawkins JN. Education and Social Change in the People's Republic of China. New York, NY: Praeger (1983).

55. Ho DY. Chinese pattern of socialization: a critical review. In: Bond MH, editor. The Psychology of Chinese People. New York, NY: Oxford University Press (1986). p. 1-37.

56. Shek DT, Lee TY, Ngai NP, Law WO, Chan LK. Assessment of perceived parenting styles, parent-adolescent conflict, and family functioning in Chinese adolescents in Hong Kong. Hong Kong J Soc Work (1995) 29:74-6.

57. Bardis PD. Familism scale. Marriage Fam Living (1959) 13:340-1. doi:10.2307/ 347107

58. Lam WW, Fielding R, McDowell I, Johnson J, Chan S, Leung GM, et al. Perspectives on family health, happiness, and harmony $(3 \mathrm{H})$ among Hong Kong Chinese people: a qualitative study. Health Educ Res (2012) 27:767-79. doi:10.1093/her/cys087

59. Shek DT. Chinese adolescents and their parents' views on a happy family: implications for family therapy. Fam Ther (2001) 28:73-104.

60. Kwok SY, Shek DT. Hopelessness, parent-adolescent communication, and suicidal ideation among Chinese adolescents in Hong Kong. Suicide Life Threat Behav (2010) 40:224-33. doi:10.1521/suli.2010.40.3.224

61. Lee MT, Wong BP, Chow BW, McBride-Chang C. Predictors of suicide ideation and depression in Hong Kong adolescents: perception of academic and family climates. Suicide Life Threat Behav (2006) 36:82-96. doi:10.1521/suli.2006.36.1. 82

62. Erikson EH. Identity: Youth and Crisis. New York, NY: Norton (1968).

63. Schwartz SJ. The evolution of Eriksonian and neo-Eriksonian identity theory and research: a review and integration. Identity (2001) 1:7-58. doi:10.1207/ S1532706XSCHWARTZ

64. Côté JE, Levine CG. Identity Formation, Agency, and Culture: A Social Psychological Synthesis. Mahwah, NJ: Erlbaum (2002).

65. Larson RW, Richards MH. Boredom in the middle school years: blaming schools versus blaming students. Am J Educ (1991) 99:418-43. doi:10.1086/443992

66. Posner JK, Vandell DL. After-school activities and the development of lowincome urban children: a longitudinal study. Dev Psychol (1999) 35:868-79. doi:10.1037/0012-1649.35.3.868

67. Denault A, Poulin F. Intensity and breadth of participation in organized activities during the adolescent years: multiple associations with youth outcomes. $J$ Youth Adolesc (2009) 38:1199-213. doi:10.1007/s10964-009-9437-5 
68. Fredricks JA, Eccles JS. Breadth of extracurricular participation and adolescent adjustment among African American and European American youth. J Res Adolesc (2010) 2:307-33. doi:10.1111/j.1532-7795.2009.00627.x

69. Gage JC, Overpeck MD, Nasel TR, Kogan MD. Peer activity in the evenings and participation in aggressive and problem behaviors. J Adolesc Health (2005) 37:517-25. doi:10.1016/j.jadohealth.2004.12.012

70. Mahoney JL. School extracurricular activity participation as a moderator in the development of antisocial patterns. Child Dev (2000) 71:502-16. doi:10.1111/ 1467-8624.00160

71. Li Y, Lerner RM. Developmental trajectories of school engagement across adolescence: implications for academic achievement, substance use, depression, and delinquency. Dev Psychol (2011) 47:233-47. doi:10.1037/a0021307

72. Dwyer KM, Richardson JL, Danley KL, Hansen WB, Sussman SY, Brannon B, et al. Characteristics of eight-grade students who initiate self-care in elementary and junior high school. Pediatrics (1990) 86:448-54.

73. Gottfredson DC, Gerstenblith SA, Soulé DA, Womer SC, Lu S. Do after school programs reduce delinquency? Prev Sci (2004) 5:253-66. doi:10.1023/B:PREV. 0000045359.41696 .02

74. Morrison GM, Storino MH, Robertson LM, Weissglass T, Dondero A. The protective function of after-school programming and parent education and support for students at-risk of substance abuse. Eval Progr Plang (2000) 23:365-71. doi:10.1016/S0149-7189(00)00025-2

Conflict of Interest Statement: The authors declare that the research was conducted in the absence of any commercial or financial relationships that could be construed as a potential conflict of interest.

Received: 18 August 2014; paper pending published: 29 August 2014; accepted: 10 September 2014; published online: 25 September 2014.

Citation: Ma CMS and Shek DTL (2014) Prevalence and psychosocial correlates of after-school activities among Chinese adolescents in Hong Kong. Front. Public Health 2:159. doi: 10.3389/fpubh.2014.00159

This article was submitted to Child Health and Human Development, a section of the journal Frontiers in Public Health.

Copyright (C) $2014 \mathrm{Ma}$ and Shek. This is an open-access article distributed under the terms of the Creative Commons Attribution License (CC BY). The use, distribution or reproduction in other forums is permitted, provided the original author(s) or licensor are credited and that the original publication in this journal is cited, in accordance with accepted academic practice. No use, distribution or reproduction is permitted which does not comply with these terms. 